\title{
A Case of Human Intestinal Spirochetosis Diagnosed During Screening Colonoscopy
}

\author{
Lynna Alnimer ${ }^{1}$, Ali Zakaria ${ }^{2}$, Bradley Warren ${ }^{2}$ \\ 1. Department of Internal Medicine, Ascension Providence Hospital, Michigan State University/College of Human \\ Medicine, Southfield, USA 2. Department of Gastroenterology, Ascension Providence Hospital, Michigan State \\ University/College of Human Medicine, Southfield, USA
}

Corresponding author: Lynna Alnimer, lynna.alnimer@gmail.com

\begin{abstract}
Human intestinal spirochetosis (HIS) is a rare disease and mostly encountered incidentally during colorectal cancer screening colonoscopy. Risk factors include homosexuality and immunocompromised states. Patients are usually asymptomatic; however, chronic diarrhea and bloody stools have been reported in some cases. Diagnosis is usually confirmed by histopathology. A watch-and-see approach is usually acceptable, but successful treatment with Metronidazole has been reported in symptomatic cases. Its clinical significance remains questionable given that patients are mostly asymptomatic.
\end{abstract}

Categories: Gastroenterology, HIV/AIDS, Infectious Disease

Keywords: human intestinal spirochetosis, spirochetes, spirochetosis, colonic biopsy, colonoscopy

\section{Introduction}

Human intestinal spirochetosis (HIS) was first described by Harland and Lee [1]. It is also known as colonic spirochetosis and refers to the colonization of the colorectal epithelium by anaerobic spirochetes, namely Brachyspira aalborgi and Brachyspira pilosicoli [2]. HIS is usually identified by pathologists in colonic biopsies but its clinical significance remains controversial [3]. Most patients are asymptomatic; however, some patients, especially immunocompromised, may present with chronic diarrhea, constipation, hematochezia, and abdominal pain [4]. We report a case of HIS in an asymptomatic 45-year-old male diagnosed incidentally during average risk colorectal cancer screening colonoscopy.

\section{Case Presentation}

This was a 45-year-old Hispanic homosexual male who presented to our endoscopy unit for an average risk colorectal cancer screening evaluation. He denied having any symptoms. Colonoscopy revealed a total of four sessile diminutive polyps; two in the descending colon, one in the transverse colon, and one in the ascending colon (Figure 1), all resected and retrieved with cold biopsy forceps.

Review began 04/27/2021 


\section{Cureus}

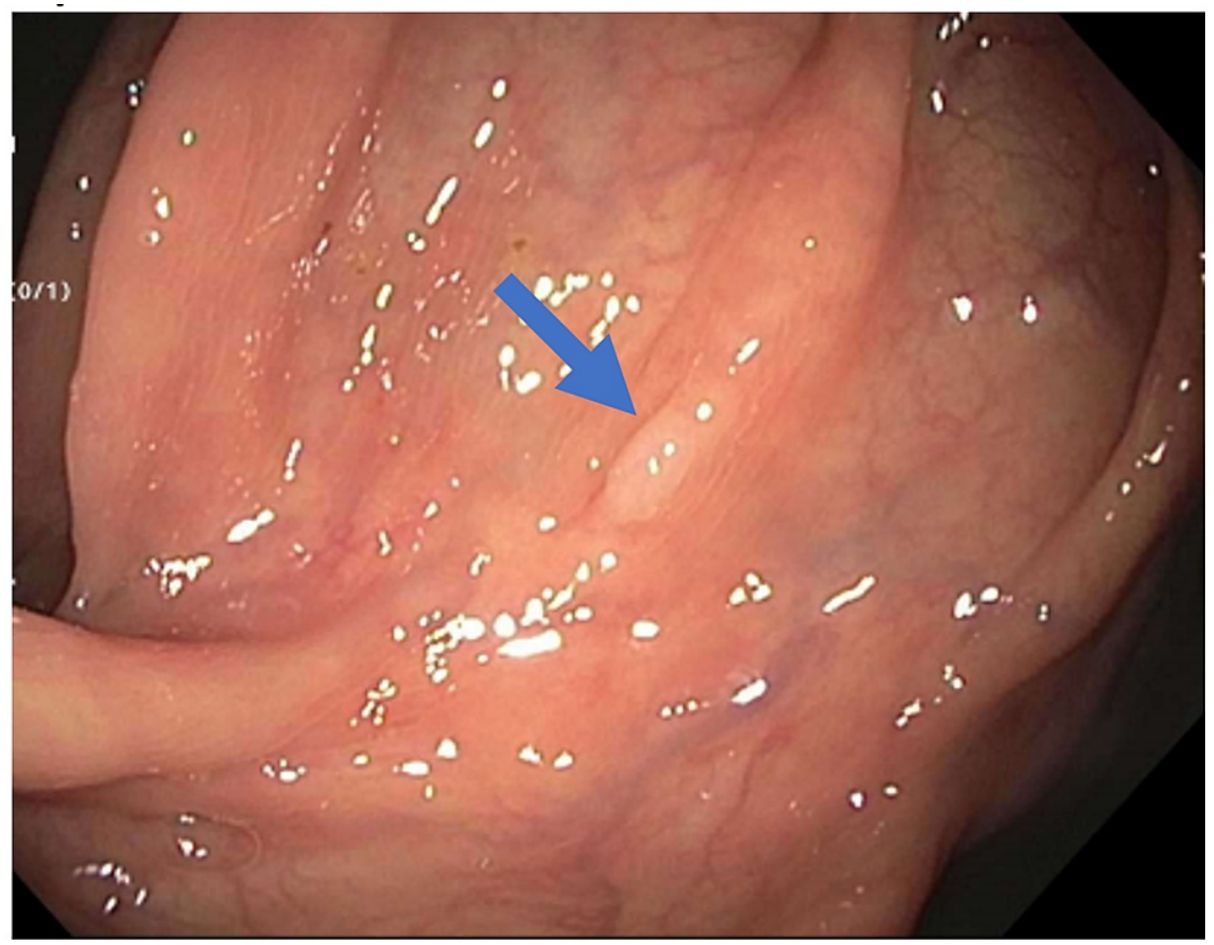

FIGURE 1: Colonoscopy view showing sessile polyp (marked with blue arrow).

Pathology showed hyperplastic polyps and Warthin Starry stain was positive for intestinal spirochetosis (Figure 2).

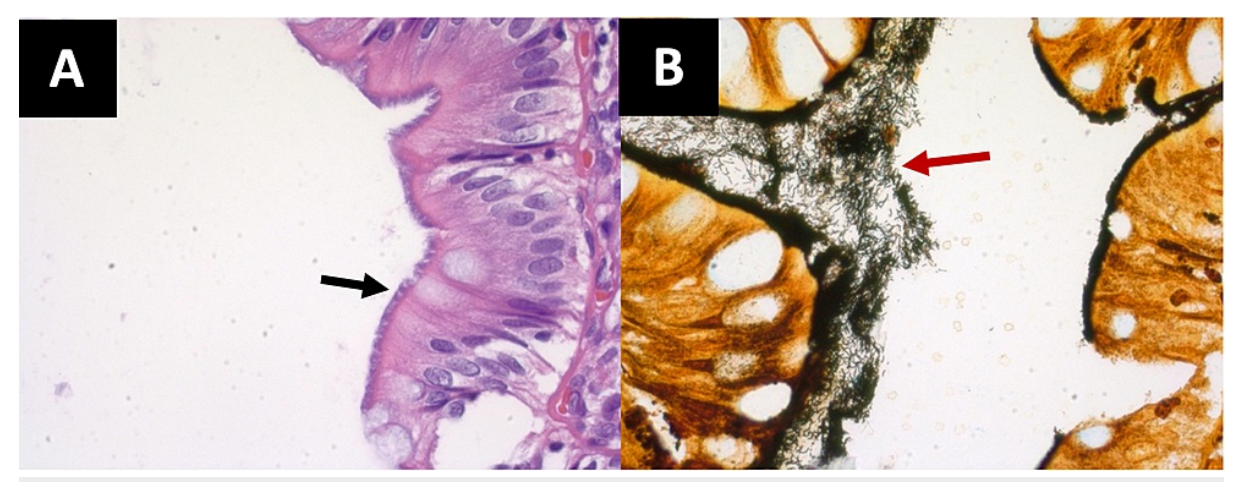

FIGURE 2: Histopathological findings with hematoxylin-eosin and Warthin-Starry staining.

(A) Hematoxylin-eosin stain (60x) highlighting filamentous structures on the epithelial surface of the colonic polyp biopsy (black arrow). (B) Spirochetes (red arrow) appear black with Warthin-Starry (Silver) stain (60x), consistent with human intestinal spirochetosis.

Given the histopathological findings, the patient was referred to an infectious disease specialist. Rapid plasma regains (RPR) and human immunodeficiency virus (HIV) were negative. The decision was to monitor the clinical condition and avoid antibiotics for the time being, given the absence of symptoms.

\section{Discussion}

Intestinal spirochetosis is common in the veterinary world causing significant symptoms yet remains a controversial topic in human medicine [5]. The prevalence of HIS in rectal biopsy specimens in Western countries is between $2 \%$ and $7 \%[6,7]$. On the other hand, the prevalence is higher in patients originating from Asia, Southern India, and West Africa [6]. In one retrospective study by Weisheit et al., the average age at diagnosis reported was 51 years [8]. 
The highest prevalence rate is in homosexual men reaching up to 54\% and in HIV-infected patients $[9,10]$. In the United States, homosexual males have shown rates of colonization up to 62.5\% [10]. This prompted clinicians to consider whether HIS is sexually transmitted. Interestingly, there did not appear to be a correlation between the degree of immunodeficiency and the severity of symptoms [11].

HIS is usually an incidental finding in most cases. However, various symptoms have been reported with the most common being chronic (watery) diarrhea $[4,8]$. Constipation, alternating diarrhea and constipation, abdominal pain, and hematochezia are other symptoms that have been described. The mechanism of diarrhea is not well understood and is believed to be non-invasive secondary to destruction of microvilli thus loss of absorptive surface [12]. Very rarely, cases of spirochetemia have been reported in immunocompromised and critically ill patients [13].

Colonic involvement has been described from the proximal to the distal colon and in the vermiform appendix [14]. A single-institution study in Japan described preference to the right colon [15]. Alsaigh and Fogt examined 15 biopsies with histologically confirmed intestinal spirochetes and demonstrated various endoscopic appearances of colonic spirochetosis including a polypoid appearance in seven patients, a lesion in one patient, and an erythematous area in one patient [16]. Some patients had HIS in normal-appearing mucosa. Graham et al. reviewed biopsies from 33 patients with HIS, and 13 of them had colonic polyps [17]. Our patient had hyperplastic polyps that are similar to findings demonstrated in other studies.

Diagnosis is traditionally based on histological examination of colonic biopsy specimens by visualization of the microorganisms using the hematoxylin-eosin (H\&E) stain under light microscopy. The abnormality is seen on the surface of the epithelium showing thread-like structures "blue fringe" in a palisade-like arrangement [5]. In addition, Warthin-Starry and Dieterle silver impregnation are other stains that can be used for further clarification [5]. On electron microscopy, the spirochetes tend to embed themselves in the colonic cells without invasion [1]. Spirochetes appear docking into the cell membrane in between destroyed microvilli [1]. Newer methods include polymerase chain reaction (PCR) amplification of a 16s rRNA to detect $B$. pilosicoli from human feces or colonic biopsy specimens and fluorescent in-situ hybridization (FISH) with oligonucleotide probes targeting 16S and 23S rRNA of B. aalborgi and B. pilosicoli [18].

In most cases, the patient is monitored without prescribing any medication. When the disease is causing severe symptoms, Metronidazole $500 \mathrm{mg}$ four times a day for 10 days can be used to treat patients [19]. Moreover, some patients did not show improvement in symptoms despite the use of antibiotics which questions the clinical significance of the disease [5]. There has been symptomatic improvement in some cases with the use of other antibiotics such as clindamycin and macrolides [20].

\section{Conclusions}

Human intestinal spirochetosis is a rare incidentally diagnosed infection yet its clinical significance remains indeterminate. HIS should be included in the differential diagnosis of immunocompromised patients presenting with chronic diarrhea. The surveillance interval colonic polyps with HIS remains an unanswered question. Since HIS is being more recognized with novel diagnostic techniques, it is anticipated that data will expand clarifying its clinical significance.

\section{Additional Information Disclosures}

Human subjects: Consent was obtained or waived by all participants in this study. Conflicts of interest: In compliance with the ICMJE uniform disclosure form, all authors declare the following: Payment/services info: All authors have declared that no financial support was received from any organization for the submitted work. Financial relationships: All authors have declared that they have no financial relationships at present or within the previous three years with any organizations that might have an interest in the submitted work. Other relationships: All authors have declared that there are no other relationships or activities that could appear to have influenced the submitted work.

\section{References}

1. Lee FD, Kraszewski A, Gordon J, Howie JG, McSeveney D, Harland WA: Intestinal spirochaetosis. Gut. 1971, 12:126-33. 10.1136/gut.12.2.126

2. Kraatz W, Thunberg U, Pettersson B, Fellström C: Human intestinal spirochetosis diagnosed with colonoscopy and analysis of partial $16 \mathrm{~S}$ rDNA sequences of involved spirochetes. Animal Health Res Rev. 2001, 2:111. 10.1079/AHRR200121

3. Christie JD: Intestinal spirochetes: organisms in search of a disease? . Am J Clin Pathol. 2003, 120:820-1. 10.1309/WDHX-RXMT-RB2P-M1J2

4. Körner M, Gebbers JO: Clinical significance of human intestinal spirochetosis: a morphologic approach . Infection. 2003, 31:341-9. 10.1007/s15010-003-3145-y

5. Tsinganou E, Gebbers JO: Human intestinal spirochetosis: a review. Ger Med Sci. 2010, 8:Doc01. $10.3205 / 000090$

6. Lee FD, Kraszewski A, Gordon J, Howie JG, McSeveney D, Harland WA: Intestinal spirochaetosis. Gut. 1971, 
12:126-33. 10.1136/gut.12.2.126

7. Nielsen RH, Orholm M, Pedersen JO, Hovind-Hougen K, Teglbjærg PS, Thaysen EH: Colorectal spirochetosis: clinical significance of the infestation. Gastroenterology. 1983, 85:62-7. 10.1016/S00165085(83)80230-3

8. Weisheit B, Bethke B, Stolte M: Human intestinal spirochetosis: analysis of the symptoms of 209 patients . Scand J Gastroenterol. 2007, 42:1422-7. 10.1080/00365520701245629

9. Trivett-Moore NL, Gilbert GL, Law CL, Trott DJ, Hampson DJ: Isolation of Serpulina pilosicoli from rectal biopsy specimens showing evidence of intestinal spirochetosis. J Clin Microbiol. 1998, 36:261-5. 10.1128/JCM.36.1.261-265.1998

10. Surawicz CM, Roberts PL, Rompalo A, Quinn TC, Holmes KK, Stamm WE: Intestinal spirochetosis in homosexual men. American J Med. 1987, 82:587-92. 10.1016/0002-9343(87)90104-5

11. Kostman JR, Patel M, Catalano E, Camacho J, Hoffpauir J, DiNubile MJ: Invasive colitis and hepatitis due to previously uncharacterized spirochetes in patients with advanced human immunodeficiency virus infection. Clin Infect Dis. 1995, 21:1159-65. 10.1093/clinids/21.5.1159

12. Cooper C, Cotton DW, Hudson MJ, Kirkham N, Wilmott FE: Rectal spirochaetosis in homosexual men: characterisation of the organism and pathophysiology. Genitourin Med. 1986, 62:47-52. 10.1136/sti.62.1.47

13. Kanavaki S, Mantadakis E, Thomakos N, Pefanis A, Matsiota-Bernard P, Karabela S, Samonis G: Brachyspira (Serpulina) pilosicoli spirochetemia in an immunocompromised patient. Infection. 2002, 30:175-7. 10.1007/s15010-002-2175-1

14. Yang M, Lapham R: Appendiceal spirochetosis. Southern Med J. 1997, 90:30-2. 10.1097/00007611199701000-00006

15. Ogata S, Shimizu K, Nakanishi K: Human intestinal spirochetosis: right-side preference in the large intestine. Ann Diagn Pathol. 2015, 19:414-7. 10.1016/j.anndiagpath.2015.10.004

16. Alsaigh N, Fogt F: Intestinal spirochetosis: clinicopathological features with review of the literature . Colorectal Dis. 2002, 4:97-100. 10.1046/i.1463-1318.2002.00284.x

17. Graham RP, Naini BV, Shah SS, Arnold CA, Kannangai R, Torbenson MS, Lam-Himlin DM: Treponema pallidum immunohistochemistry is positive in human intestinal spirochetosis. Diagn Pathol. 2018, 13:7. 10.1186/s13000-017-0676-6

18. Jensen TK, Boye M, Ahrens P, Korsager B, Teglbjaerg PS, Lindboe CF, Møller K: Diagnostic examination of human intestinal spirochetosis by fluorescent in situ hybridization for Brachyspira aalborgi, Brachyspira pilosicoli, and other species of the genus Brachyspira (Serpulina). J Clin Microbiol. 2001, 39:4111-8. 10.1128/JCM.39.11.4111-4118.2001

19. Guzman Rojas P, Catania J, Parikh J, Phung TC, Speth G: Intestinal spirochetosis in an immunocompetent patient. Cureus. 2018, 10:e2328. 10.7759/cureus.2328

20. Marthinsen L, Willén R, Carlén B, Lindberg E, Värendh G: Intestinal spirochetosis in eight pediatric patients from Southern Sweden. APMIS. 2002, 110:571-9. 10.1034/j.1600-0463.2002.11007809.x 